\title{
2 All roads lead to directional cell
}

\section{3 migration}

4

5

6 Adam Shellard and Roberto Mayor*

7

8

9

10

11

12

13

14

15

16

17

18

19

20

21 Street, London WC1E 6BT, UK

Department of Cell and Developmental Biology, University College London, Gower

${ }^{*}$ Corresponding author. Correspondence and request for materials should be addressed to R.M. (Email: r.mayor@ucl.ac.uk) 


\section{Abstract}

2 Directional cell migration normally relies on a variety of external signals, such as 3 chemical, mechanical or electrical, which instruct cells in which direction to move.

4 Many of the major molecular and physical effects derived from these cues are now 5 understood, leading to questions about whether directional cell migration is alike or 6 distinct under these different signals, and how cells might be directed by multiple 7 simultaneous cues, which would be expected in complex in vivo environments. In 8 this review, we compare how different stimuli are spatially distributed, often as 9 gradients, to direct cell movement and the mechanisms by which they steer cells. A 10 comparison of the downstream effectors of directional cues suggests that different 11 external signals regulate a common set of components: small GTPases and the actin 12 cytoskeleton, which implies that the mechanisms downstream of different signals are 13 likely to be closely related and underlies the idea that cell migration operates by a common set of physical principles, irrespective of the input.

Keywords: migration, chemotaxis, durotaxis, galvanotaxis, haptotaxis, gradients 


\section{Directional cell migration}

Cell migration orchestrates key events in development, homeostasis and disease [1]. Cells can move individually [2] or as collectives [3]. The direction in which cells move is rarely random; in most cases, migration occurs in a highly directional manner, whereby cells translocate from one specific location to another. For example, immune cells move towards sites of infection, bacteria migrate toward nutrient sources; radial glia cells, germ cells and neural crest cells migrate long distances to form tissues and organs in the developing embryo, and directional migration also occurs during wound healing and cancer invasion (Fig. 1).

Cells have the intrinsic capacity to move directionally in vitro [2], but in vivo, they encounter a complex microenvironment with an enormous array of cues. Thus, it is believed that most directional migration relies on cells responding to localised, external stimuli. This is called '-taxis' (plural '-taxes'; see Glossary), which is Greek for 'arrangement'. Migration of cells has been described in response to a huge number stimuli, which generally fall into the categories of chemical, mechanical and electrical and in recent years, many new modes of directional migration have been described (Table 1). With a growing appreciation that cells are likely to encounter different types of cues simultaneously, this review will outline the best described of these: chemotaxis, galvanotaxis, haptotaxis and durotaxis, which refers to migration along gradients of chemical cues, electric fields, immobilised chemokines and mechanical stiffness, respectively. We will discuss how gradients of stimuli can be spatially generated, describe the models and mechanisms by which they operate, and compare to what extent they direct cell motility via common or distinct pathways, effectors and molecular components. The evidence suggests that gradients of these cues are likely to operate at a short range, potentially self-generated by the migratory cells themselves, and that different types of stimuli act on common cellular and molecular components to regulate cell migration. This comparison may provide insights of how newly discovered directional cues may act, and how cues might cooperate or compete to regulate directional motility in vivo.

\section{Principles of cell migration}

The principal concepts underlying adherent cell migration are well understood (Fig. 2) [4]. In order for a cell to migrate directionally it needs to become polarized, 
1 meaning the front becomes distinct from the back of the cell (Fig 2A,B). Fundamental

2 to this breaking of symmetry is actin polymerisation at the leading edge, driving membrane outgrowth (Fig. 2B), called protrusions, which adhere to the substrate by focal contacts. Bundles of actin filaments containing myosin II motors, called stress fibres, connect to focal contacts and generate contractile forces that mature the adhesion (Fig. 2C), with the forces transferring onto the substrate in the form of traction. At the rear of the cell, focal adhesions disassemble and the cell body and nucleus retract (Fig. 2D). The forces of actin polymerisation and myosin contractility together drives the cell forward. The organisation of these forces and motility processes depends on small GTPases. Cdc42 is a regulator of cell polarity, whereas Rac coordinates actin polymerisation at the front by activating SCAR/WAVE and the actin nucleator complex Arp2/3. RhoA regulates actomyosin contractility and rear retraction. Similar physical principles are believed to underpin collective cell migration, in which large-scale forces are propagated across cell groups by an actin cytoskeleton that is connected across cells via intercellular junctions [5]. Non-adherent cells are also capable of migration: instead of force coming from stress fibres, the cell is propelled forward by contractility and retrograde flow of the cell cortex [6]. By lowering high levels of active Rac, competitive forces via randomly distributed protrusions are prevented, meaning cells have the capacity to migrate directionally in vitro even in absence of external guidances [7]. However, in vivo, it remains unknow whether cells undergo intrinsic directional migration as cells are subjected to an enormous array of extracellular cues in their microenvironment. Instead, evidence suggest that directional migration in vivo is coordinated by extracellular cues.

\section{How are stimuli spatially established?}

Extracellular stimuli are spatially organised to direct cells to specific locations. In this section, we will examine how these signals are set up.

\section{Chemotactic gradients}

Cell migration up gradients of soluble chemical signals, such as growth factors or chemokines, is called chemotaxis (Fig. 3A). The classical idea of chemotactic gradients posits that they are set up by a source that produces chemoattractant and a sink which removes it [8]. Thus, a high to low concentration attractant gradient runs 
1 from the source to sink, respectively. In this model, the gradient is externally

2 generated, and the migratory cells simply respond to this externally-generated gradient. The cells producing the attractant would normally be non-migrating cells that are the target destination for the migratory cells, but may also be another migratory cell population [9]. Although such conditions can be generated in vitro, it is unlikely that this mechanism could explain long distance migration in vivo. Cells undergoing chemotaxis normally adjust the distribution of guidance cues with enzymes (e.g. by degradation with MMPs or ADAMs) $[10,11]$ or by endocytosing them with its receptors, while still responding to them [12], which suggests that the responding cells are actively involved in shaping the gradient.

An attractive model of chemotactic gradients is one in which the gradient is selfgenerated: the gradient is generated by the migratory cells themselves [13]. In this model, cells degrade an initially homogeneous chemoattractant, meaning regions of high cell density have low levels of chemoattractant (Fig. 3B). This degradation combined with diffusion of the chemoattractant self-generates a gradient [10, 11]. In doing so, the gradient is constantly moving with the cells; the cells are continually pursuing a retreating region of high chemoattractant concentration. This mechanism makes chemotaxis very robust [14], and may underly the migration of many cell types, including Dictyostelium and interneurons [15-17]. Chemotaxis is only efficient at attractant concentrations near the dissociation constant $(\mathrm{Kd})$ of the receptors. Shallow gradients are too flat for cells to resolve, whereas steep gradients lead to saturation at the cells chemotax, meaning chemotaxis is only efficient over short distances, which further supports the idea of self-generated chemotactic gradients. Indeed, chemotaxis of the lateral line primordium in vivo relies on attractant concentration values being similar to the $\mathrm{Kd}$ of its receptor [18], whereas higher or lower attractant levels result in less directional migration. In this case, the migrating cells self-generate the gradient by buffering the levels of chemokine around the $\mathrm{Kd}$ of its receptors by regulating local attractant levels via feedback between the receptor and another decoy (clearance) receptor [18]. An alternative mechanism involves adjusting the receptor's $\mathrm{Kd}$ to the local chemoattractant concentration to increase their dynamic range, like in dendritic cells and bacteria [19, 20]. Some cells can resolve $1 \%$ differences in receptor occupancy between their fronts and rears, and self-generated gradients can be computationally simulated based on a $1 \%$ difference 
1 in sensitivity between the front and back [16, 21, 22]. Even in artificially steep

2 gradients in vitro, which are not thought to be reflective of in vivo gradients, front-rear ligand-receptor binding differences are less than 20\% [21]. Such self-generated gradients have been proposed to explain cell movement in complex environments [23], like that which is encountered in vivo.

6 Apart from degradation of the chemoattractant by the moving cells, there are other ways in which cells can self-generate a chemotactic gradient. Even though chemotaxis is typically paracrine, meaning cells secrete chemoattractant that affects the behaviour of their local neighbours, cells can release migration-enhancing factors at the front, which positively feedback onto the leader cells themselves in an in a subset of the cell population, like leader cells, and potentially express decoy receptors in another subset, such as follower cells [12, 25]. For example, collective migration of the lateral line relies on the expression of CXCR7 receptor scavenger at the rear, whereas CXCR4 receptor at the front responds to stromal cell-derived factor 1 (SDF1), which self-generates the gradient $[12,26]$. Thus, collective effects may sense gradients differently than single cells [3].

Dynamic short-range gradients can also be produced by dynamic behaviour of the chemoattractant-producing cells. Cranial neural crest cells undergo short-range chemotaxis to placodal cells that produce the chemoattractant SDF1 [9]. Repulsion between the two cell populations causes the co-migration of both neural crest cells and placodal cells [9]. Thus, short-range and self-generated chemotactic gradients can produce highly dynamic and persistent directional cell migration.

\section{Durotactic gradients}

Environmental mechanics is known to regulate many cell functions, including migration [27]. Cells' ability to move along stiffness gradients is called durotaxis (Fig. $3 C)$. Various techniques have been developed in recent years to produce stiffness gradients in vitro [28], and these have been used to demonstrate durotaxis for various cell types [29-31]. However, while stiffness gradients have been observed in vivo and cell migration can correlate with this gradient, how durotactic gradients could be set up remains largely speculative. 
1 One possibility is that gradients are externally generated to which the migratory cells respond. In the mouse limb bud, Wnt5a expressed by the ectoderm and distal mesenchyme spatially biases the expression of fibronectin, which generates a stiffness gradient [32]. Stiffness is also known to be associated with cell density in vivo (Fig. 3D), as demonstrated in the mouse spinal cord and the Xenopus mesoderm during neurulation [33, 34]. The stiffness gradient of the embryonic Xenopus brain is also proposed to originate from changes in cell body density, whereby differential proliferation results in a cell density gradient along the axis [35].

An alternative possibility is that stiffness gradients are self-generated by the migratory cells themselves. Cells are known to modify the mechanical properties of the extracellular matrix (ECM) [36], which implies that extracellular stiffness is likely to be actively modified by surrounding cells (Fig. 3D) or by the moving cells themselves. Thus, cells can engage in a positive feedback loop of regulating and responding to extracellular stiffness. High matrix stiffness triggers mechanosensitive pathways, like the Hippo pathway in fibroblasts [37] and in various tissues during fibrosis [38], which leads to increased ECM production, deposition and crosslinking [39]. The alignment of pre-existing and cell-deposited matrix fibres is also part of a feedback loop that further stiffens the ECM [40]. Furthermore, extracellular stiffening can mediate protein splicing which contributes to matrix remodelling and cell migration [41]; and stiffness can modulate MMP expression and activity, which degrades the matrix [41, 42]. Thus, multiple types of feedback mechanisms exist by which cells could potentially alter stiffness for durotaxis.

\section{Haptotactic gradients}

Haptotactic migration refers to movement of cells up a gradient of cellular adhesion sites or substrate-bound cues, like cytokines and chemokines (Fig. 3E). Gradients of adhesive sites are naturally present in the ECM [43, 44]. Theoretically, gradients for haptotaxis may be produced by similar means to gradients for chemotaxis. Cells can secrete factors that diffuse through extracellular spaces and immobilise on extracellular matrices (Fig. 3F). When such factors are produced by localised sources, diffusion is sufficient to produce immobilised gradients to which cells can respond, such as the CCL21 gradient produced from lymphatic endothelial cells in vivo [19, 45], or CXCL8 gradients that guide neutrophils in zebrafish [46]. Variations 
1 in extracellular matrix components, such as fibronectin or collagen concentration, can also drive haptotaxis $[47,48]$.

The responsive, migratory cells may also remodel the matrix themselves and modify the haptotactic gradient. For instance, pericytes contribute basement membrane components that may affect their haptotaxis to endothelial cell tubes [49] and keratinocytes deposit laminin- $V$ onto dermal collagen, thereby overriding and changing the adhesive signal which can instruct keratinocytes themselves to migrate during wound healing [50]. Furthermore, Schwann cells deposit laminin and migrate on it in a concentration-dependent manner [51]. Such remodelling of the ECM can also involve removal of adhesion sites, thereby affecting haptotaxis. Endothelial cells break down fibronectin locally, migrating into regions of higher fibronectin concentration by haptotaxis during angiogenesis [52]. Matrix remodelling can also involve deposition of oriented or disoriented fibres which can affect cell alignment and directionality [53]. Thus, it is likely that cells undergoing haptotaxis are actively remodelling the haptotactic gradient to which they respond.

Haptotaxis may be a highly robust means of cell guidance, because gradients of immobilised factors are insensitive to mechanical perturbations. Moreover, the fact that many chemokines can bind to components of the ECM [54] suggests haptotaxis could be a widely used principle.

Like for other signals, haptotactic sensing depends on the steepness and shape of the gradient, consistent with a scenario whereby cellular directionality is governed by local signal-to-noise ratio of the cue i.e. cells detect differences in bound receptors at the front and rear [19].

\section{Galvanotactic gradients}

Cells can move in response to electric fields, a process known as galvanotaxis (Fig. 3G). Tissues exhibit an endogenous electric potential difference due to ions and charged particles flowing out of tissues. For instance, active $\mathrm{N}^{+} / \mathrm{K}^{+}$ATPase pumps and $\mathrm{Cl}^{-}$channels generate and maintain an endogenous transcutaneous electric potential in epithelial layers of the skin and cornea [55] (Fig. 3H). Such endogenous bioelectric fields are evident during tissue regeneration and development in vivo [5658]. 
1 Injury makes a gap that penetrates the high electrical resistance established and

2 maintained by tight junctions, resulting in charged particles and ions, including $\mathrm{Na}^{+}$,

$3 \mathrm{Cl}^{-}, \mathrm{K}^{+}$and $\mathrm{Ca}^{2+}$ ions, to leak across wounded cells or cell layers, which short-circuits

4 the epithelium locally [59]. Consequently, the potential difference drops to zero but

5

6

7 because ion transport continues in unwounded epithelium, potential differences remain at normal values from the wound edge. Thus, asymmetric flows of charged particles and ions establishes a weak electrical current and a voltage gradient (difference in electrical potential across space) laterally oriented at wounds (Fig. $3 \mathrm{H}$ ).

This gradient of electrical potential difference from wounded to unwounded tissue establishes a steady, laterally oriented electric field with the cathode at the wound [55]. Electric fields can be considered self-generated in that the same disrupted cells that generate the gradients of weak electric current are themselves responsive to it; migrating into open spaces by galvanotaxis [60]. Besides the epithelium itself, endothelial and neuronal cells located near the wound also move by galvanotaxis for tissue regeneration $[60,61]$, which suggests cells can may be able to respond to electric fields in their local environment, even if they were not self-generated.

Such endogenous electric fields generated at epithelial wounds are an intrinsic property of all transporting epithelia that separate ions and sustain a transepithelial potential difference. Electrical fields have been measured in vivo [62]. Electrical potential differences have been found in various tissues and electric fields have been detected in limb stumps and skin wounds [55, 61].

Altogether, the evidence of how gradients are generated by these different cues suggests that while classical long-range gradients may be sufficient to mediate directional motility in vitro, local gradients, potentially generated by the migratory cells themselves or others, may predominate in vivo.

\section{Mechanisms of directional migration}

In this section, we will discuss the models and molecular mechanisms at play during the directional migration of cells toward these various extracellular cues.

\section{Chemotactic mechanisms}


1 The mechanisms of chemotaxis are the best understood of any cue [63-66]. Signal

2 transduction events by chemotaxis have been highly studied in Dictyostelium, dendritic cells, neutrophils, neurons and germ cells. The known mechanisms are extensive and varied, depending on cell type and context.

5 Chemotactic signals are sensed by the binding of membrane-bound receptors to the extracellular cue. Their activation triggers diverse intracellular signalling pathways [65]. Receptors are activated more in the region of the cell where there is higher chemoattractant, meaning the downstream intracellular signals are polarised. Consequently, many proteins are recruited specifically to the leading or trailing edges [67] (Fig. 4A). Classically, PI3K and Akt signalling is enhanced at the front, protrusions thanks to increased actin polymerisation via WAVE and Arp2/3 [68]. An alternative mechanism is that this downstream signalling locally stabilises transiently generated protrusions, whereas randomly generated protrusions in other regions of the cells are not stabilised. The signalling bias caused by high ligand-receptor binding compared to other parts of the cell results in biased direction or retention of protrusions, which coordinates directional migration [21, 69]. PI3K activity at the front is coupled to restricted distribution of its antagonist, PTEN, to the rear [70]. Rho is also active at the cell rear, where, together will local calcium signalling, it regulates actomyosin contractility and cell retraction [68].

The molecular changes instigated by a graded chemical signal have physical implications. Stimulation of Rac enhances protrusive forces as well as encouraging the formation of adhesions on the substrate to generate traction [63]. Chemoattractants enhance the formation focal complexes at the leading edge, by acting on Rac and Cdc42, which stabilise the lamellipodia by attaching it to the ECM, which ultimately drives forward motion [63]. Focal adhesion assembly and disassembly is also mediated by Rho [63], which promotes stress fibre contractility, encouraging the cell to generate directionally oriented traction forces that cause the cell to move in the direction of chemoattractant.

It should be noted that in addition to the above described mechanisms of chemotactic polarisation and force generation, many other mechanisms have been 
1 described to be important for chemotaxis, including $\mathrm{pH}$, calcium signalling and microtubules and other elements of the cell's cytoskeleton [71-73].

\section{Durotactic mechanisms}

Actomyosin stress fibres, which are stress-generating units, are anchored to the extracellular matrix via focal adhesion complexes, which allows them to apply forces onto the substrate [74] (Fig. 4B). Thus, many of the molecular components important for durotaxis are those at the cell-ECM interface, including integrins, FAK, paxillin and vinculin [75]. The forces exerted through focal adhesions to probe the stiffness of the substrate is exerted in a dynamically fluctuating manner of the focal adhesion [75], a mechanism that is specific to durotaxis and not required for chemotaxis or haptotaxis, illustrating the fact that durotaxis is a mechanical response. Contractile pulling forces from stress fibres that are anchored to stiff regions have resistance, which encourages focal adhesion growth, whereas protrusions that land on soft substrates only form transient focal contacts. There is also large-scale reorganisation of the actin cytoskeleton to orient in the direction of most traction as a result of this mechanical feedback. Other than integrins, mechanosensitive proteins, like the ion channel Piezo1, may also mediate the durotactic response [35]. Regulators of the actin cytoskeleton are also critical for durotaxis. The complex, Arp2/3, promotes actin polymerisation at the front which leads to cell stretching and lamellipodial extension [29]. Actin polymerisation is boosted at focal adhesions by Ena/VASP family members to promote mechanosensing [76]. Many of these components are regulated by small GTPases. For example, Rac1 (and its effector cdGAP) regulates rigidity sensing by controlling protrusion and adhesion dynamics [77], while RhoA controls cell retraction at the rear [78]. Rho can be indirectly activated due to low membrane tension, which occurs at the rear of a cell that is on graded stiffness [78]. By comparison, high membrane tension from stiff substrates may activate Piezo, leading to calcium influx, thereby mediating a range of local intracellular processes, like strengthened focal adhesions when calcium spikes promote local myosin contractility.

Through these signalling networks, effector proteins like PKA and YAP become activated, leading to changes in protein activation and dynamics, as well as gene expression changes, which are crucial for normal durotaxis [79, 80]. 
1 Importantly, durotaxis is a response to mechanics rather than chemicals, meaning how such molecules work together to enable durotaxis is not trivial. Various models have been proposed [28]. Because cell speed and persistence increase with extracellular rigidity for some cell types, one model suggests that guidance of cells is simply a consequence of increased persistence, rather than stiffness acting as a guidance cue, and to reflect that, the phenomenon should be renamed durokinesis [81]. Mechanistically, this may work because cells are more polarised on stiffer substrates, leading to a restricted (narrower) distribution of focal contacts and therefore a tendency for cells to move to stiffer substrates as they move around, becoming increasingly persistent in their motion [82]. An alternative model, built on classical models of migration that emphasise adhesive strength, is based on thermodynamics. Forces applied to protein complexes, like focal adhesions, result in stretching the corresponding proteins leading to accumulation of elastic stress, which is coincident with the insertion of new proteins into the aggregate resulting in stress relaxation. Thus, the growth of focal adhesions, a process that is proportional to and dependent on stress and due to protein self-assembly, has reduced chemical potential compared to unaggregated molecules [83]. Therefore, self-assembly of proteins is favoured when pulling forces act and disfavoured when relaxed. Under these circumstances, durotaxis would be a phenomenon of stress fibres, in which focal adhesions become more stable on stiffer substrates than on softer ones [84, 85]. A third model posits that applications of similar force onto the ECM will deform stiff substrates less than soft substrates [30, 86, 87]. Cytoskeletal connection between the cell front and rear would result in forward movement of the cell centre. This model is a development of the previously described 'clutch model' in which the cytoskeleton acts as a clutch that transmits force to the ECM $[86,88]$ and has been used to explain durotaxis of epithelial cell sheets [87]. Because focal adhesion size may be unrelated to the force they exert on the substrate [89], this mechanism would work entirely by differential deformation of the ECM.

It is not clear how cells may sense stiffness gradients in vivo and potentially titrate active forces to coordinate cell movements. In vitro, cells can discern a large range of stiffness gradients [87, 90], including physiologically relevant stiffness gradients [91]. Durotaxis depends mostly on the strength of the gradient itself and is mostly independent of the absolute substrate stiffness in vitro [30, 31, 35, 92]. Cells migrate 
1 more efficiently on steeper gradients, where there is higher signal to noise ratio, than on shallower gradients, where the signal-to-noise is lower [31]. It is suggested that the pathway downstream of focal adhesion kinase (FAK), a component of the focal adhesion complex, broadens the range of rigidities over which durotaxis operates [75].

\section{Haptotactic mechanisms}

7

During haptotaxis, cells sense differences in ECM concentration or engagement across a single cell, and then react by polarising their cytoskeletal and motility machinery to enable them to protrude and migrate up the gradient towards fixed substrate-bound cues. Hence, many of the molecules identified as important for this type of migration are like those of chemotaxis and durotaxis, when the stimulus is an extracellular matrix component or an immobilised ligand, respectively.

Components of the focal adhesion complex, including integrins, FAK and Src are necessary for haptotaxis and enter a positive feedback loop with regulators of the actomyosin cytoskeleton, including WAVE, Tiam1, Rac and the Arp2/3 complex, which promote lamellipodial protrusions [93, 94] (Fig. 4C). Arp2/3 and these lamellipodial protrusions are crucial for haptotaxis [93]. They are formed in all directions but are reinforced when they protrude up the gradient towards higher ECM thanks to focal adhesion feedback [94]. Focal adhesions fail to align in Arp2/3 depleted cells, suggesting one principle function of lamellipodia is to organise cellmatrix adhesions in a spatially coherent manner [93]. Myosin IIB is also necessary for haptotaxis, by coordinating protrusive activities and stabilising cell polarity [95].

One specific directional migration sensor for haptotaxis is liver kinase B1 (LKB1), and its effectors MARK/PAR-1. Their activation is necessary for haptotaxis and they are required to detect inhibitory matrix cues [96].

\section{Galvanotactic mechanisms}

The precise mechanisms for galvanotaxis are largely unknown. Initially, galvanotactic movement was proposed to occur thanks to the movement of charged molecules. However, this model is now seen as incomplete because the direction of charged molecules in cells does not always coincide with the direction of cell movement [97]. 
1 Galvanotaxis is now viewed as a complex process that signifies the combined outcome of many mechanisms. The primary physical mechanism is believed to be through electrophoretic redistribution of charged membrane components [98]. Various migration-inducing membrane receptors including ConA, EGFR, VEGFR, ROR2, integrins, and AchR are polarised when exposed to an electric field [55, 61, 99]. Such redistribution of membrane components causes polarised and local activation of intracellular signalling molecules, such as MAPK/ERK1/2, pERK1/2, PI3K/Akt, and PTEN [60, 100] (Fig. 4D). Thus, many proteins are actively relocated during galvanotaxis and such asymmetries give cells polarity, activating the Rac, Cdc42 and Rho, which causes cells to form protrusions by actin polymerisation and migrate directionally [101]. For instance, PI3K and PTEN are key molecules that mediate electrotactic response: where PI3K is activated, cells make membrane protrusions and directed migration ensues, whereas PTEN prevents this happening in the opposite direction [60].

Other mechanisms involved in galvanotaxis include asymmetric ion fluxes and preferential activation of voltage-gate ion channels [101]. Electric fields can asymmetrically open voltage-gated channels and pumps, like the $\mathrm{Na}^{+}-\mathrm{K}^{+}$ATPase, $\mathrm{NHE} 3$ and $\mathrm{Ca}^{2+}$ or $\mathrm{Na}^{+}$ion channels, which results in ion flux and downstream signalling that affect cytoskeletal polarisation $[61,100]$. Some channels, such as the $\mathrm{K}^{+}$channel, Kir4.2, specifically control galvanotaxis without affecting motility and directional migration [102]. They do so via their action of PI3K/Akt signalling, which affects actin polymerisation and protrusion formation. These molecules can therefore couple electric fields to activation of intracellular molecules.

Overall, polarised signalling is likely to be a general mechanism of galvanotaxis to locally polymerise actin and elicit directional cell migration [60, 99]. However, ECM interactions have also been shown to modulate galvanotaxis; myosin II and PI3K hold strikingly differentiate roles in different microenvironments [103].

\section{Many stimuli: common effectors?}

Many of the molecular components involved in directional migration by different types of cues have been identified. However, cells are likely to be exposed to chemical, mechanical and electrical signals altogether. For example, during wound healing, chemotactic, galvanotactic, haptotactic and durotactic migration have all 
1 been proposed to operate. Do such diverse signals ultimately control directional cell migration by common or distinct components?

Detection of these cues is inherently different. Chemotactic and haptotactic growth factors are sensed by membrane-bound receptors; the ECM is bound to focal adhesion complexes via integrin engagement during durotaxis and haptotaxis; and electric fields can affect cellular components without any molecular engagement at all during galvanotaxis. In all cases, downstream of these pathways lies regulation of small GTPases and of the actin cytoskeleton (Fig. 4E).

Molecular attractants in chemotaxis and haptotaxis promote leading edge Rac activity through conserved signalling pathways, which leads to actin polymerisation and formation of front-directed protrusions [94, 104, 105]. Rac and Cdc42 are involved in matrix rigidity sensing for durotaxis by controlling membrane protrusions and adhesion dynamics [77], and polarised Rac activity is essential for galvanotaxis [103, 105]. Electric fields modulate PI3K and MAPK signalling by redistribution of membrane components and ion channel activation, meaning small GTPases are highly manipulated during galvanotaxis to control migration in various systems [106108].

In durotaxis, stress fibre contractility, which is normally mediated by RhoA, is the means by which forces are applied on the substrate [28]. Active RhoA also controls fast cellular retraction during durotaxis [79]. These activities of RhoA are also evident and required for haptotaxis and chemotaxis [109, 110]. In chemotaxis, enhanced RhoA at the rear encourages the assembly of actin stress fibres and focal adhesions and a similar mechanism operates in haptotaxis $[109,110]$. Galvanotactic signals also perpendicularly orient actin stress fibres, likely by recruitment of ROCK and PTEN at the rear [111]. This stress reorientation precedes cell body reorientation [112] during cell guidance. Thus, extracellular stimuli regulate the contractile forces exerted by the cell to successfully navigate them towards the signal.

Such common effects on small GTPases and the actin cytoskeleton are also observed in more newly discovered - and less well-known - guidance cues, like curvotaxis, topotaxis and ratchetaxis, in which cell symmetry is locally broken at the scale of the individual cell based on local topology (curvature, topographic features, or spatially patterned adhesive regions, respectively) and guided as a result [113, 
1 114]. This relies on Rho GTPase activity. Specifically, the actin polymerisation regulator Cdc42 and the branched actin nucleator Arp2/3 complex are essential for curvotaxis [115]. The signalling networks of PI3K and ROCK that control topotaxis, in which direction of migration is mediated by gradients of topographic features, are known to regulate cell migration via Rho GTPases and therefore it is proposed that topotaxis likely works by similar downstream canonical mechanisms of small GTPases and actin regulation [116]. Directional migration by means of spatially determined adhesion sites may be related to the organisation of stress fibers that allows them to organise their forces to pass through an asymmetric topology [117]. These recently describing topological guidance cues are likely to be highly relevant in vivo, where distributions of adhesive sites are not homogeneous [118].

RhoA is also likely to regulate viscotaxis, which refers to migration in response to a gradient of loss modulus. Loss modulus is a measure of dissipated energy, represented by the viscosity of materials. Actomyosin contractility is essential for this form of directional migration [119]; and RhoA regulates myosin activity through ROCK.

Overall, the evidence points to the idea that small GTPase regulation downstream of extracellular signals is a means of controlling the actin cytoskeleton and hence direct cell motion. Additionally, they are likely to be involved in the cell's sensation of the signal, for example, Rho promoting force generation of stress fibres to probe the mechanical properties of the environment.

Cells are likely to be in receipt on many different types of cues in vivo, thanks to the complexity of the microenvironment, so it is conceivable that different stimuli compete or cooperate by regulating common cell components. Only a handful of studies have so far investigated how multiple cues affect cell migration. Cytokine and growth factor gradients have a cooperative role in regulating 3D invasion of cancer cells [120]. The interplay between topology and molecular cues has also been studied. A topological ratchet, in which a spatial patterning of adhesive regions controls directional migration by controlling cell shape and thus the distribution of focal contacts, can act cooperatively or competitively with a haptotaic fibronectin concentration gradient [121]. When the gradients align, directional migration is enhanced, whereas if they are spatially opposed, directional migration is stalled. 
1 Additionally, a chemical gradient in the opposite direction to the ratchet can drive the cells to move 'against' the favourable direction of motion as set up by the ratchet of adhesive sites, whereas when the chemotactic gradient is removed, the cells fail to continue moving in this direction [117]. Likewise, topotactic and chemotactic cues have additive effects on the directional migration of Dictyostelium [122]. There is nothing known about the interplay between chemical and mechanical signals, although chemotaxis overwhelmingly overrides barotaxis during directional decision making in Dictyostelium [123]. Altogether, these recent results indicate that directional cues are likely to cooperate or compete to guide cells in vivo, and may operate through long-range or local signals [113]. The molecular or physical mechanisms by which these interactions occur is an open question.

\section{Concluding remarks}

Directional migration can be controlled by a huge range of different stimuli. There are lots of avenues for future research (see Outstanding Questions) but nonetheless common themes have emerged in the establishment, regulation and cellular can be spatially established and actively shaped by both migratory cells and by other 'source' cells. To what extent this happens in vivo is still a relatively unaddressed question. Chemical and mechanical signals are sensed and responded to by somewhat similar components. In particular, small GTPases, and the polarity and actin cytoskeleton that they regulate form the fundamental basis of a directional motility response. It is tantalising to propose that a single cellular mechanism operates at centre of the directional response to various cues, but more likely is that such varied stimuli use small GTPases and the actin cytoskeleton in different ways to achieve the same outcome of directional motion. 


\section{Glossary}

2 Taxis: Greek for 'arrangement'; plural 'taxes' is the movement of cells in response to a stimulus. Many different cellular taxes have been described (Table 1).

Chemotaxis: directional migration along a gradient of soluble chemical cues. The first description of chemotaxis was made by Engelmann and Pfeffer in bacteria over a century ago $[124,125]$. Since then, repulsive and attractive cues have been found for a variety of processes, including Dictoystelium, bacteria, neurons, immune cells germ cells and neural crest cells. Chemotax is the by far the best understood form of directional migration, although chemotaxis may not account for all directional migration in vivo.

Durotaxis: directed migration along a stiffness gradient, specifically from soft substrates to stiff ones (durus is Latin for hard). Research into durotaxis was made possible thanks to the development of techniques that produce hydrogels of differing stiffnesses, which led to the first demonstration of durotaxis in fibroblasts at the turn of the century[126]. Durotaxis has been shown for a few different cell types in vitro [29-31] but, so far, there is no in vivo evidence of cellular durotaxis. That being said, durotactic gradients might be relevant in vivo; stiffness gradients have been observed in the mouse limb bud [32] and during fibrosis [127]. Durotaxis has also been proposed to underly epithelial spreading in morphogenesis [128].

Galvanotaxis: directional migration in response to an electric field. The discovery that cells undergo galvanotaxis in a specific direction relative to the direct-current (d.c.) electric field dates to the nineteenth century [129]. Galvanotactic in vitro studies have been performed primarily using galvanotaxis chambers in which agar salt bridges couple current into a shallow channel containing cells. It has been shown for many cell types in vitro, including fibroblasts, endothelial and epithelial cells, neurons, immune cells and cancer cells [55]. Most cells migrate to the cathode, whereas a few migrate towards the anode. Galvanotaxis can also occur in vivo. Many cells are responsive to voltages as low as that which is within the physiological range [99] and disruption of these electric fields alters development and prevents regeneration and healing, indicating that galvanotaxis is an important mode of directional migration. 
1 Haptotaxis: directional migration up a gradient of cellular adhesion sites or substrate-bound cytokines and chemoattractants. Haptotaxis was named after 'haptein' to reflect that cells were navigating in response to the relative strength of the adhesive contacts made with the substrate [130]. Cells usually orient their migration toward increasing availability of adhesion sites in vitro; however, cells may also orient towards decreasing ligand density depending on cell type and adhesion receptors involved [96, 131]. Various cell types have been shown to undergo haptotaxis in vitro [132, 133]. Most chemokines bind to extracellular substrates [54] so it is reasonable to assume that immobilisation is decisive in vivo. Gradients of substrate-bound factors have been identified in vivo and are believed to control haptotaxis, including in angiogenesis [134], the immune response [45, 46] and wound closure $[135,136]$.

SCAR/WAVE: a WASP family member that induces actin nucleation via recruitment and activation of the Arp2/3 complex.

Arp2/3: a protein complex that acts as an actin nucleator, allowing the formation of new actin filaments from pre-existing actin filaments.

Rac: a small GTPase that drives plasma membrane extension through actin polymerisation via WAVE/SCAR and the Arp2/3 complex [137].

Rho: a small GTPase that promotes formation of larger, more persistent integrinbased adhesions and regulates actomyosin contractility [137].

Cdc42: a small GTPase involved in filopodial protrusion formation, cell polarity, actomyosin contractility and focal adhesion assembly [137].

Small GTPases: master regulators of cell migration, coordinating the activity of signalling pathways and the cytoskeleton [137]. The three most well known small GTPases are Rac, Rho and Cdc42. 
1 Table 1. Different cellular stimuli.

\begin{tabular}{|c|c|c|c|c|c|}
\hline Taxis & Etymology & Synonyms & $\begin{array}{l}\text { Definition } \\
\text { (directional } \\
\text { migration-) }\end{array}$ & Example(s) & References \\
\hline Chemotaxis & $\begin{array}{l}\text { Chemo - } \\
\text { chemical }\end{array}$ & & $\begin{array}{l}\text { By soluble } \\
\text { chemical } \\
\text { cues }\end{array}$ & $\begin{array}{l}\text { Posterior lateral } \\
\text { line primordium, } \\
\text { immune cells, } \\
\text { neural crest } \\
\text { cells, primordial } \\
\text { germ cells, } \\
\text { Dictyostelium, } \\
\text { dendritic cells, } \\
\text { bacteria, } \\
\text { leukocytes, } \\
\text { neurons }\end{array}$ & $\begin{array}{l}{[66,138-} \\
140]\end{array}$ \\
\hline Durotaxis & Duro - hard & $\begin{array}{l}\text { Mechanotaxis } \\
\text { (depending } \\
\text { on definition) }\end{array}$ & By stiffness & $\begin{array}{l}\text { Epithelial } \\
\text { sheets, smooth } \\
\text { muscle cells, } \\
\text { fibroblasts }\end{array}$ & {$[87,126]$} \\
\hline Galvanotaxis & $\begin{array}{l}\text { Galvano- } \\
\text { galvanism }\end{array}$ & Electrotaxis & $\begin{array}{l}\text { By electric } \\
\text { current }\end{array}$ & $\begin{array}{l}\text { Dictyostelium, } \\
\text { fibroblasts, } \\
\text { epithelial cells }\end{array}$ & $\begin{array}{l}{[55,61,} \\
129]\end{array}$ \\
\hline Energy taxis & & & $\begin{array}{l}\text { By } \\
\text { metabolic } \\
\text { activity }\end{array}$ & Bacteria & [141] \\
\hline Gravitaxis & & Geotaxis & By gravity & Euglena & [142] \\
\hline Magnetotaxis & $\begin{array}{l}\text { Magneto - } \\
\text { magneto- } \\
\text { electric }\end{array}$ & & $\begin{array}{l}\text { By magnetic } \\
\text { field }\end{array}$ & Bacteria & [143] \\
\hline Phototaxis & Photo - light & & By light & Chlamydomonas & {$[144]$} \\
\hline Rheotaxis & Rheo - flow & & By fluid flow & Sperm & [145] \\
\hline Aerotaxis & Aero - air & & $\begin{array}{l}\text { Stimulation } \\
\text { by oxygen }\end{array}$ & Bacteria & [146] \\
\hline
\end{tabular}




\begin{tabular}{|c|c|c|c|c|c|}
\hline Barotaxis & Baro - weight & & By pressure & Neutrophils & [147] \\
\hline Hydrotaxis & Hydro - water & & By moisture & Bacteria & [148] \\
\hline Thermotaxis & $\begin{array}{l}\text { Thermo - } \\
\text { heat }\end{array}$ & & $\begin{array}{l}\text { By } \\
\text { temperature }\end{array}$ & Dictyostelium & [149] \\
\hline Thigmotaxis & $\begin{array}{l}\text { Thigmo - } \\
\text { touch }\end{array}$ & & $\begin{array}{l}\text { By physical } \\
\text { contact }\end{array}$ & $\begin{array}{l}\text { Paramecium } \\
\text { bursaria }\end{array}$ & [150] \\
\hline Haptotaxis & Hapto - touch & & $\begin{array}{l}\text { By adhesion } \\
\text { sites or } \\
\text { substrate- } \\
\text { bound } \\
\text { chemical } \\
\text { cues }\end{array}$ & $\begin{array}{l}\text { Dendritic cells, } \\
\text { leukocytes }\end{array}$ & $\begin{array}{l}{[45,46,} \\
130]\end{array}$ \\
\hline Curvotaxis & Curvus - bent & & $\begin{array}{l}\text { By } \\
\text { curvature }\end{array}$ & $\begin{array}{l}\text { Mesenchymal } \\
\text { cells }\end{array}$ & [115] \\
\hline Topotaxis & $\begin{array}{l}\text { Topo - } \\
\text { topographic }\end{array}$ & & $\begin{array}{l}\text { By density } \\
\text { of ECM } \\
\text { fibres }\end{array}$ & $\begin{array}{l}\text { Fibroblasts, } \\
\text { melanomas }\end{array}$ & [116] \\
\hline Mechanotaxis & $\begin{array}{l}\text { Mechano - } \\
\text { mechanical }\end{array}$ & $\begin{array}{l}\text { Durotaxis } \\
\text { (depending } \\
\text { on definition) }\end{array}$ & $\begin{array}{l}\text { By } \\
\text { mechanics, } \\
\text { or by } \\
\text { stiffness, or } \\
\text { by shear } \\
\text { stress }\end{array}$ & Endothelial cells & [151] \\
\hline Viscotaxis & $\begin{array}{l}\text { Visco - } \\
\text { viscous }\end{array}$ & & $\begin{array}{l}\text { By } \\
\text { substrate } \\
\text { loss } \\
\text { modulus }\end{array}$ & $\begin{array}{l}\text { Mesenchymal } \\
\text { stem cells }\end{array}$ & [119] \\
\hline Plithotaxis & $\begin{array}{l}\text { Plithos - } \\
\text { crowd }\end{array}$ & & $\begin{array}{l}\text { By maximal } \\
\text { principal } \\
\text { stress }\end{array}$ & $\begin{array}{l}\text { Epithelial cell } \\
\text { lines e.g. MDCK } \\
\text { cells, breast } \\
\text { cancer cells }\end{array}$ & [152] \\
\hline Ratchetaxis & Ratchet & & $\begin{array}{l}\text { By local and } \\
\text { repeated }\end{array}$ & Fibroblasts & [114] \\
\hline
\end{tabular}


anisotropic

environment

1 


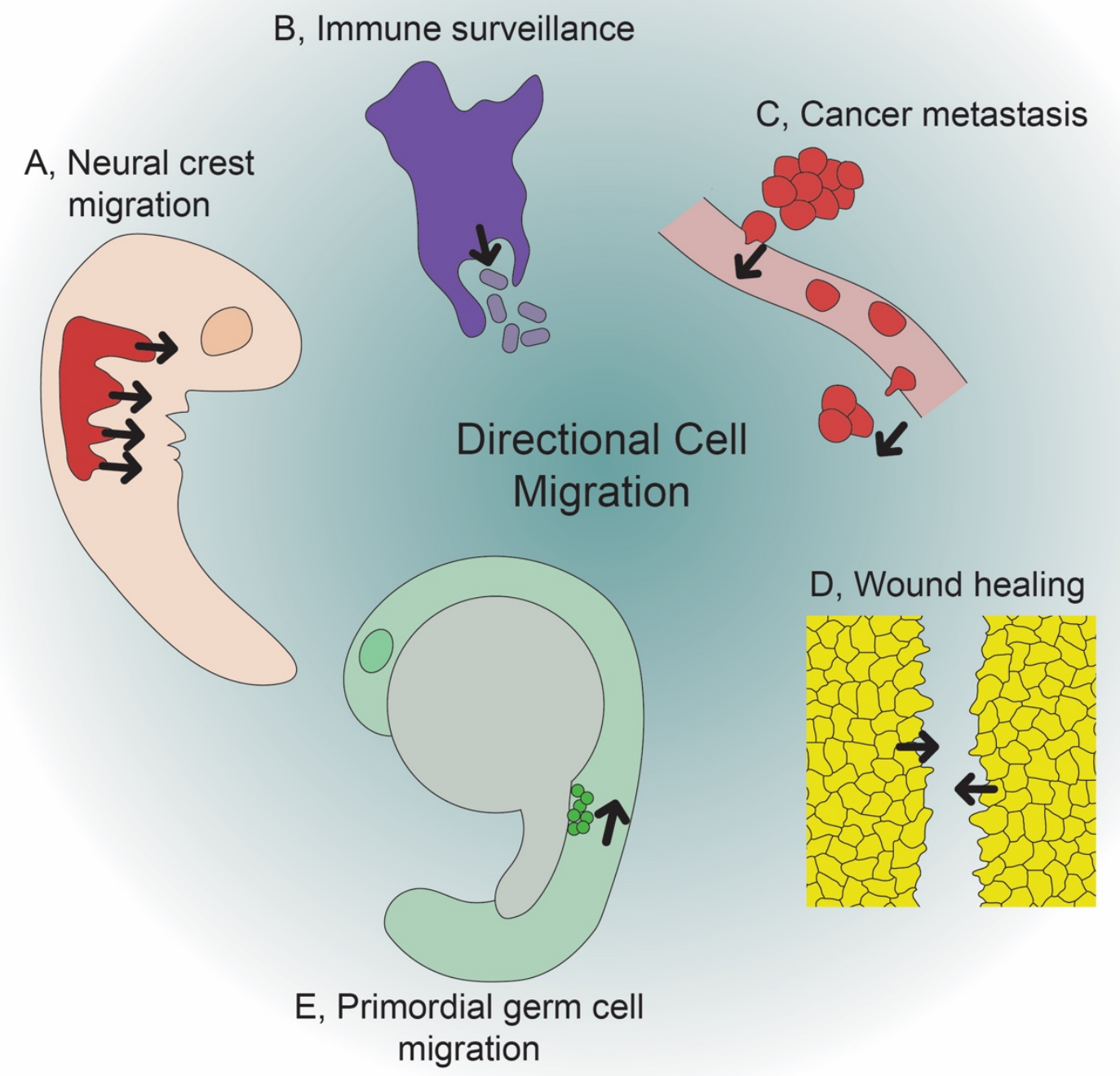

3 Figure 1. Importance of directional migration. Cells move (black arrow) 4 individually and collectively by directional migration during development, 5 homeostasis and disease. A, Neural crest cell migration; B, immune surveillance; C, 6 cancer metastasis; D, wound healing; E, primordial germ cell migration. 

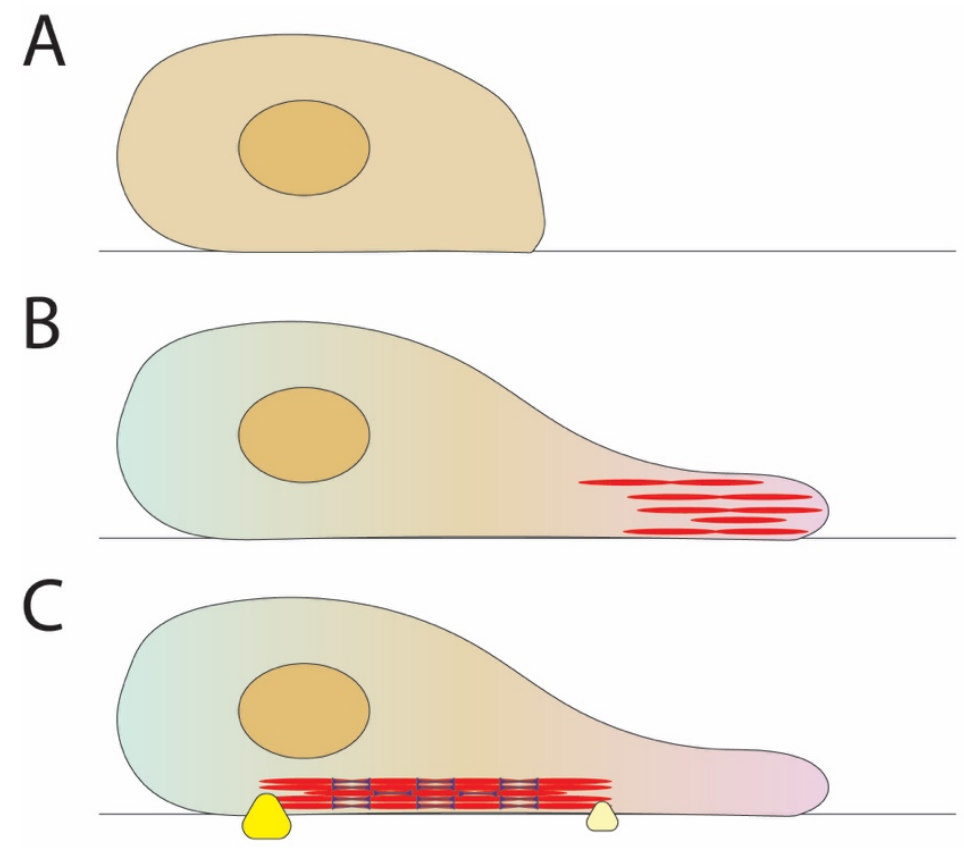

D
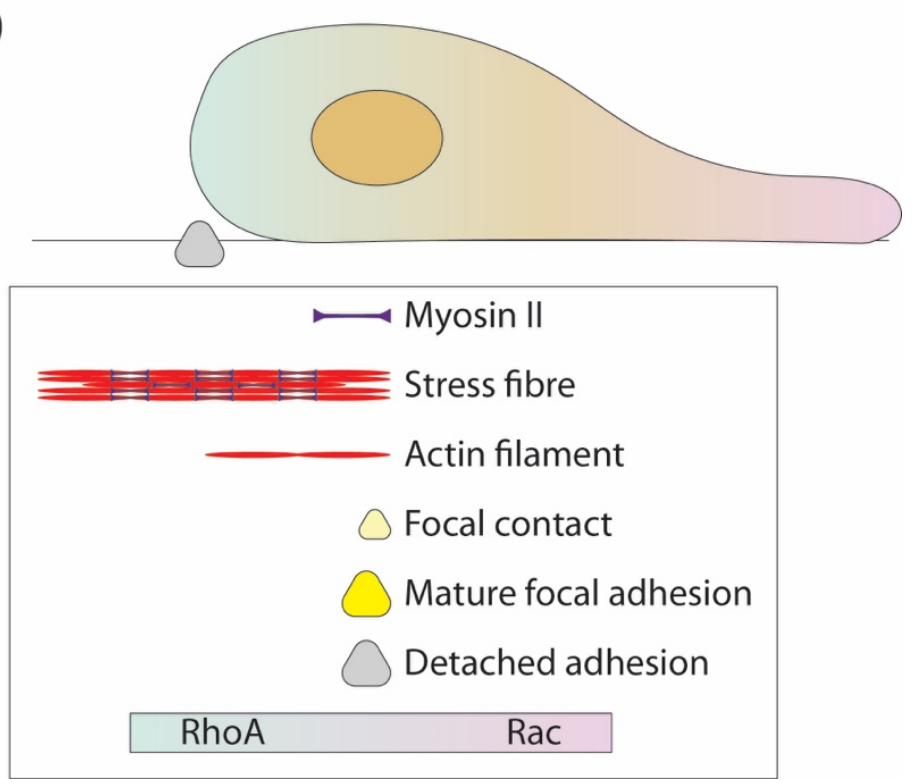

Figure 2. Basic principles of adherent cell migration. A, An unpolarised cell. B, Upon intrinsic polarity or extracellular cues, the small GTPase Rac coordinates polymerisation of actin filaments by activating WAVE and Arp2/3. This generates protrusive forces that push on the cell membrane. $\mathbf{C}$, Actin filaments in the protrusion connect with focal complexes, anchor the cell to the substrate and begin to stabilise the protrusion. Actin filaments bundle together and associated with the myosin II motor proteins, called stress fibres. Stress fibres generate forces that are transferred via focal contacts with the underlying substrate, thereby producing traction that moves the cell forward. Stress on focal contacts leads to their maturation and enlargement in focal adhesions, a process dependent on RhoA. D, RhoA-mediated contractile forces retract the cell rear, pushing the cell body forward, leading to detachment of cell-substrate adhesions at the trailing edge. Cdc42 also polarises the cell, and simultaneous protrusive and contractile forces by the actin cytoskeleton spatially coordinated by small GTPases drives cell movement. Key, bottom. 

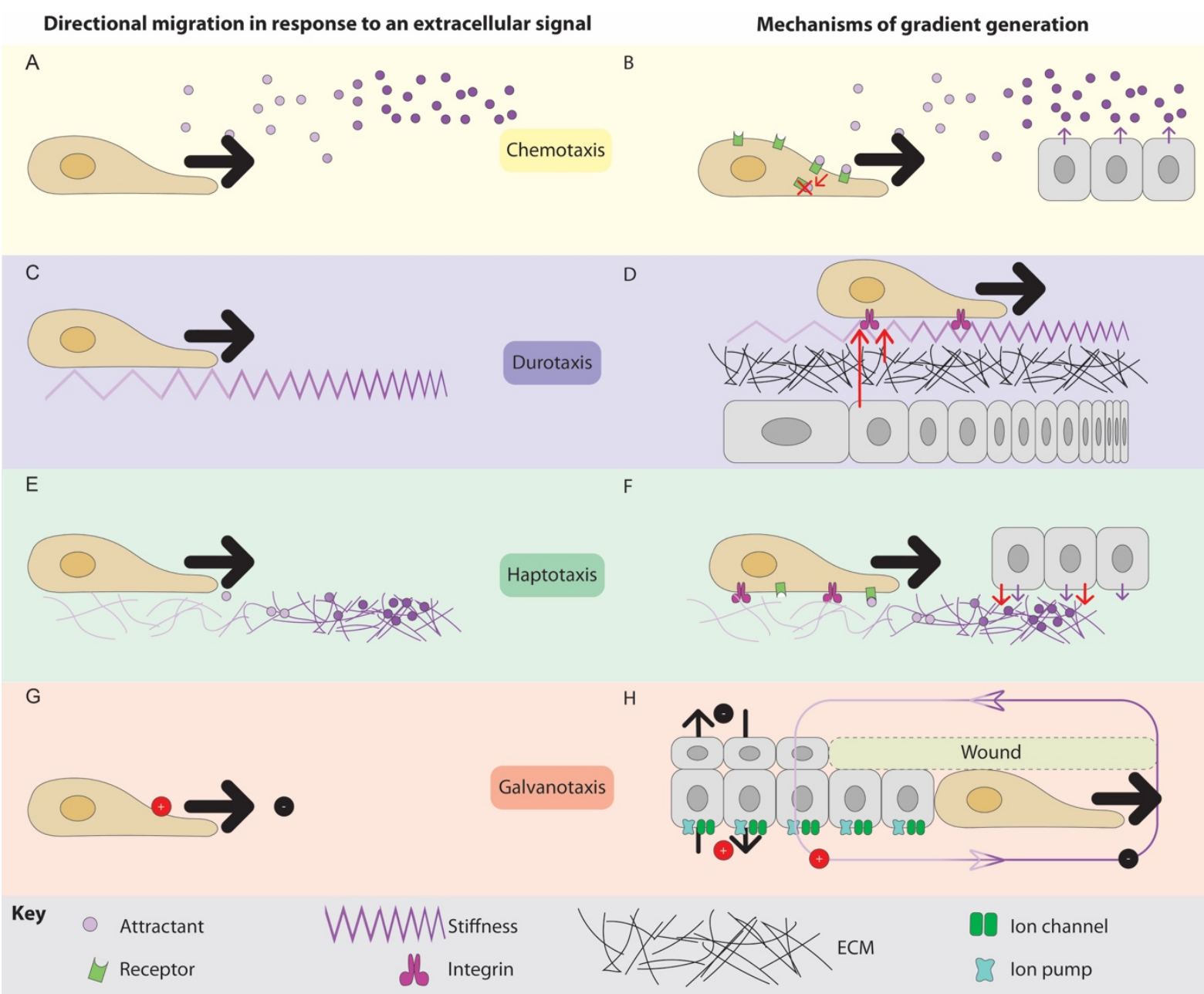

2 Figure 3. Gradient formation of migratory cues. A, In chemotaxis, cells migrate (black arrow) up a gradient (light purple to dark purple) of soluble chemical cues (circles). B, Chemoattractant can be produced (purple arrows) by the migratory cells themselves (orange cell) or others (grey cells). The gradient is set up by diffusion and actively by endocytosis and degradation (red arrow and red cross) after it binds to a receptor (green square). C, In durotaxis, cells migrate up a gradient of extracellular stiffness (spikes). D, The best-understood mechanism of regulating stiffness is by modifying the extracellular matrix (black lines) such as deposition, cross-linking, degradation and orientation of fibres (red arrow from matrix to stiffness). Cell density can also contribute to the stiffness detected by a cell (red arrow from grey cells to stiffness). Stiffness is mechanically probed via integrins (purple digits). E, In haptotaxis, cells migrate up a gradient of cellular adhesions sites (matrix lines) or substrate-bound cues (circles). F, The principles of shaping a haptotactic gradient are likely to be similar to the remodelling of the extracellular matrix described in (d). G, In galvanotaxis, cells migrate in response to an electric field. Come cells migrate toward the cathode whereas others migrate toward the anode. $\mathbf{H}$, Tissues normally have a transepithelial potential generated by the flow of different ions (thin black arrows) through channels (green ovals) and pumps (blue star). Wounding (green rectangle) results in ion leakage and the formation of an electric field (purple circuit) from the tissue to the wound opening that triggers migration. 
A Chemotaxis

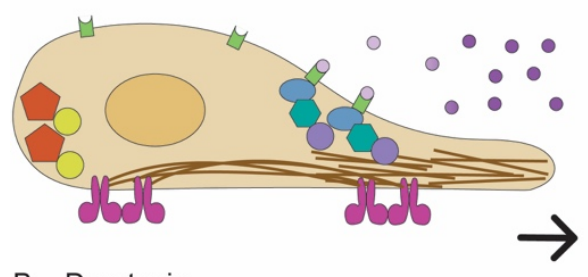

B Durotaxis

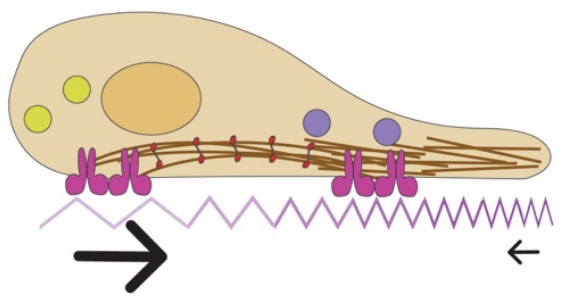

E Small GTPases and the actin cytoskeleton as central regulators

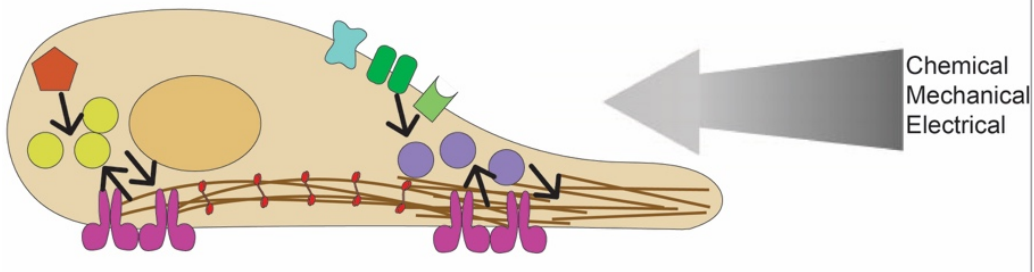
response to various types of stimuli.
C Haptotaxis
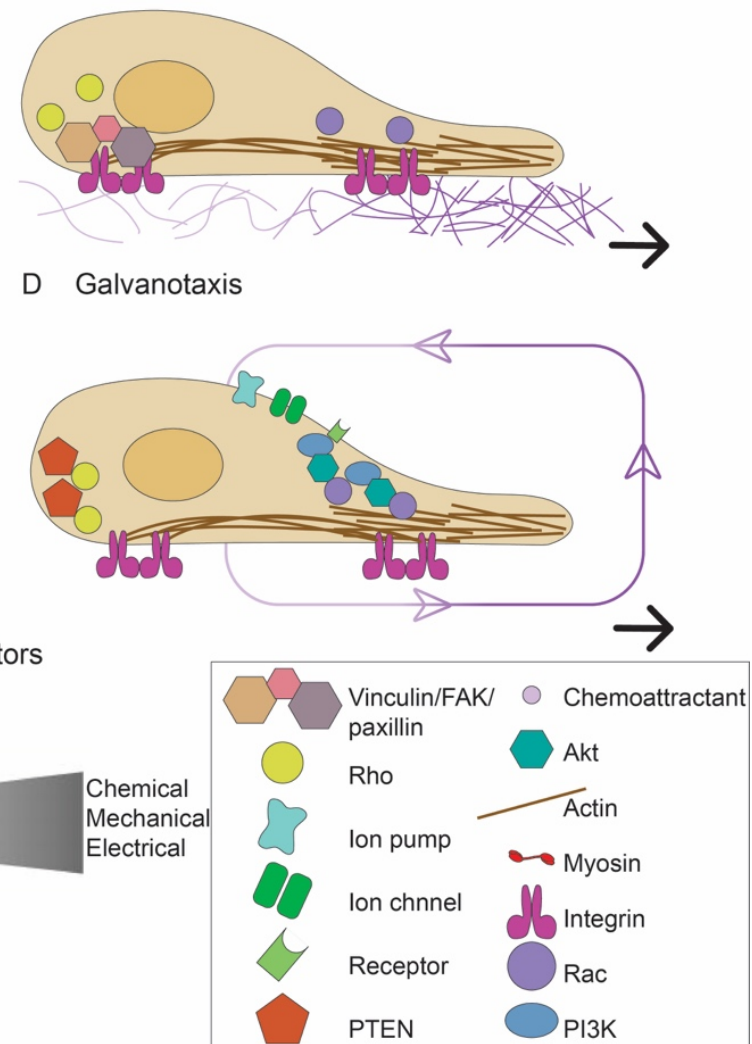

Figure 4. Mechanisms of directional migration. A key of symbols is in the bottom right. A, In chemotaxis, chemoattractants bind to membrane-bound receptors. There is more ligand-bound receptor at the front of the cell than at its rear, which leads to polarised signalling. Classical chemotaxis signalling involves activation of PI3K and Akt signalling at the front, which leads to Rac activity and actin polymerisation. At the cell rear, PI3K is absent, so PTEN is unaffected, which promotes Rho activity and actomyosin contraction. B, During durotaxis, actomyosin stress fibres produce forces on the extracellular matrix through focal adhesion complexes (composed of molecules including vinculin, FAK and paxillin) and integrins. Forces applied on the substrate drive the cell forward, with contraction on stiffer substrates leading to less extracellular deformation than contraction on softer substrates. Rho is essential for this myosin-dependent process. Rac is involved in formation of new membrane protrusions, which provide new area for mechanosensation. C, Cells detecting gradients of immobilised ligands exhibit similar molecular pathways to those observed during chemotaxis. By comparison, focal adhesions are used to detect gradients in extracellular adhesion sites. Importantly, haptotaxis relies on chemical transduction, whereas durotaxis models propose mechanical transduction. D, Upon exposure to electric fields, there is electrophoretic redistribution and activation of membrane components and signalling pathways, as well as activation of voltagegated channels, as well as ion pumps ant transporters. These changes lead to polarised Rac and Rho activity which leads to directional migration. E, Rac and Rho are the principle mediators of directional migration by extracellular cues. Their modification of the actin cytoskeleton in particular drives directional migration in 


\section{Data accessibility}

2 This article has no additional data.

3 Competing interests

$4 \quad$ We have no competing interests.

$5 \quad$ Funding

6 Work in RM laboratory is supported by grants from the Medical Research Council

7 (MR/S007792/1), Biotechnology and Biological Sciences Research Council

8 (M008517) and Wellcome Trust (102489/Z/13/Z).

9 
1. Yamada, K.M. and Sixt, M. (2019) Mechanisms of 3D cell migration. Nature Reviews Molecular Cell Biology 20 (12), 738-752.

2. Petrie, R.J. et al. (2009) Random versus directionally persistent cell migration. Nature Reviews Molecular Cell Biology 10 (8), 538-549.

3. Haeger, A. et al. (2015) Collective cell migration: guidance principles and hierarchies. Trends in Cell Biology 25 (9), 556-566.

4. Ridley, A.J. et al. (2003) Cell migration: Integrating signals from front to back. Science 302 (5651), 1704-1709.

5. Mayor, R. and Etienne-Manneville, S. (2016) The front and rear of collective cell migration. Nature Reviews Molecular Cell Biology 17 (2), 97-109.

6. Paluch, E.K. et al. (2016) Focal Adhesion-Independent Cell Migration. Annual Review of Cell and Developmental Biology, Vol 32 32, 469-490.

7. Pankov, R. et al. (2005) A Rac switch regulates random versus directionally persistent cell migration. Journal of Cell Biology 170 (5), 793-802.

8. Crick, F. (1970) DIFFUSION IN EMBRYOGENESIS. Nature 225 (5231), 420-\&.

9. Theveneau, E. et al. (2013) Chase-and-run between adjacent cell populations promotes directional collective migration. Nature Cell Biology 15 (7), 763-+.

10. Muinonen-Martin, A.J. et al. (2014) Melanoma Cells Break Down LPA to Establish Local Gradients That Drive Chemotactic Dispersal. Plos Biology 12 (10).

11. Garcia, G.L. et al. (2009) The Group Migration of Dictyostelium Cells Is Regulated by Extracellular Chemoattractant Degradation. Molecular Biology of the Cell 20 (14), 3295-3304.

12. Dona, E. et al. (2013) Directional tissue migration through a self-generated chemokine gradient. Nature 503 (7475), 285-+.

13. Tweedy, L. et al. (2016) Self-generated chemotactic gradients - cells steering themselves. Current Opinion in Cell Biology 42, 46-51.

14. Tweedy, L. and Insall, R.H. (2020) Self-Generated Gradients Yield Exceptionally Robust Steering Cues. Frontiers in Cell and Developmental Biology 8.

15. Saaber, F. et al. (2019) ACKR3 Regulation of Neuronal Migration Requires ACKR3 Phosphorylation, but Not beta-Arrestin. Cell Reports 26 (6), 1473-+.

16. Tweedy, L. et al. (2016) Self-Generated Chemoattractant Gradients: Attractant Depletion Extends the Range and Robustness of Chemotaxis. Plos Biology 14 (3).

17. Sanchez-Alcaniz, J.A. et al. (2011) Cxcr7 Controls Neuronal Migration by Regulating Chemokine Responsiveness. Neuron 69 (1), 77-90.

18. Lau, S. et al. (2020) A negative-feedback loop maintains optimal chemokine concentrations for directional cell migration. Nature Cell Biology 22 (3), 266-+.

19. Schwarz, J. et al. (2017) Dendritic Cells Interpret Haptotactic Chemokine Gradients in a Manner Governed by Signal-to-Noise Ratio and Dependent on GRK6. Current Biology 27 (9), 1314-1325.

20. Bourret, R.B. et al. (1991) SIGNAL TRANSDUCTION PATHWAYS INVOLVING PROTEINPHOSPHORYLATION IN PROKARYOTES. Annual Review of Biochemistry 60, 401-441.

21. Insall, R.H. (2010) Understanding eukaryotic chemotaxis: a pseudopod-centred view. Nature Reviews Molecular Cell Biology 11 (6), 453-458.

22. Zigmond, S.H. (1977) ABILITY OF POLYMORPHONUCLEAR LEUKOCYTES TO ORIENT IN GRADIENTS OF CHEMOTACTIC FACTORS. Journal of Cell Biology 75 (2), 606-616.

23. Tweedy, L. et al. (2019) Seeing around corners: Cells create chemotactic gradients to solve mazes and respond to distant cues in complex environments. bioRxiv. https://doi.org/10.1101/836056.

24. Majumdar, R. et al. (2014) New paradigms in the establishment and maintenance of gradients during directed cell migration. Current Opinion in Cell Biology 30, 33-40.

25. Cai, D. and Montell, D.J. (2014) Diverse and dynamic sources and sinks in gradient formation and directed migration. Current Opinion in Cell Biology 30, 91-98.

26. Venkiteswaran, G. et al. (2013) Generation and Dynamics of an Endogenous, Self-Generated Signaling Gradient across a Migrating Tissue. Cell 155 (3), 674-687. 
27. Charras, G. and Sahai, E. (2014) Physical influences of the extracellular environment on cell migration. Nature Reviews Molecular Cell Biology 15 (12), 813-824.

28. Sunyer, R. and Trepat, X. (2020) Durotaxis. Current Biology 30 (9), R383-R387.

29. DuChez, B.J. et al. (2019) Durotaxis by Human Cancer Cells. Biophysical Journal 116 (4), 670-683. 30. Bollmann, L. et al. (2015) Microglia mechanics: immune activation alters traction forces and durotaxis. Frontiers in Cellular Neuroscience 9.

31. Isenberg, B.C. et al. (2009) Vascular Smooth Muscle Cell Durotaxis Depends on Substrate Stiffness Gradient Strength. Biophysical Journal 97 (5), 1313-1322.

32. Zhu, M. et al. (2020) Spatial mapping of tissue properties in vivo reveals a 3D stiffness gradient in the mouse limb bud. Proceedings of the National Academy of Sciences of the United States of America 117 (9), 4781-4791.

33. Barriga, E.H. et al. (2018) Tissue stiffening coordinates morphogenesis by triggering collective cell migration in vivo. Nature 554 (7693), 523-+.

34. Weickenmeier, J. et al. (2016) Brain stiffness increases with myelin content. Acta Biomaterialia 42, 265-272.

35. Koser, D.E. et al. (2016) Mechanosensing is critical for axon growth in the developing brain. Nature Neuroscience 19 (12), 1592-1598.

36. Wullkopf, L. et al. (2018) Cancer cells' ability to mechanically adjust to extracellular matrix stiffness correlates with their invasive potential. Molecular Biology of the Cell 29 (20), 2378-2385.

37. Noguchi, S. et al. (2017) TAZ contributes to pulmonary fibrosis by activating profibrotic functions of lung fibroblasts. Scientific Reports 7.

38. Lee, M.J. et al. (2014) YAP and TAZ Regulate Skin Wound Healing. Journal of Investigative Dermatology 134 (2), 518-525.

39. Kothapalli, D. et al. (2012) Cardiovascular Protection by ApoE and ApoE-HDL Linked to Suppression of ECM Gene Expression and Arterial Stiffening. Cell Reports 2 (5), 1259-1271.

40. Sander, E.A. et al. (2011) Initial Fiber Alignment Pattern Alters Extracellular Matrix Synthesis in Fibroblast-Populated Fibrin Gel Cruciforms and Correlates with Predicted Tension. Annals of Biomedical Engineering 39 (2), 714-729.

41. Bordeleau, F. et al. (2017) Matrix stiffening promotes a tumor vasculature phenotype. Proceedings of the National Academy of Sciences of the United States of America 114 (3), 492-497.

42. Haage, A. and Schneider, I.C. (2014) Cellular contractility and extracellular matrix stiffness regulate matrix metalloproteinase activity in pancreatic cancer cells. Faseb Journal 28 (8), 3589-3599.

43. Sawicka, K.M. et al. (2015) Fibronectin Interaction and Enhancement of Growth Factors: Importance for Wound Healing. Advances in Wound Care 4 (8), 469-478.

44. Kostourou, V. and Papalazarou, V. (2014) Non-collagenous ECM proteins in blood vessel morphogenesis and cancer. Biochimica Et Biophysica Acta-General Subjects 1840 (8), 2403-2413.

45. Weber, M. et al. (2013) Interstitial Dendritic Cell Guidance by Haptotactic Chemokine Gradients. Science 339 (6117), 328-332.

46. Sarris, M. et al. (2012) Inflammatory Chemokines Direct and Restrict Leukocyte Migration within Live Tissues as Glycan-Bound Gradients. Current Biology 22 (24), 2375-2382.

47. Smith, J.T. et al. (2006) Directed cell migration on fibronectin gradients: Effect of gradient slope. Experimental Cell Research 312 (13), 2424-2432.

48. Hsu, S. et al. (2005) Effects of shear stress on endothelial cell haptotaxis on micropatterned surfaces. Biochemical and Biophysical Research Communications 337 (1), 401-409.

49. Stratman, A.N. and Davis, G.E. (2012) Endothelial Cell-Pericyte Interactions Stimulate Basement Membrane Matrix Assembly: Influence on Vascular Tube Remodeling, Maturation, and Stabilization. Microscopy and Microanalysis 18 (1), 68-80.

50. Nguyen, B.P. et al. (2000) Deposition of laminin 5 in epidermal wounds regulates integrin signaling and adhesion. Current Opinion in Cell Biology 12 (5), 554-562.

51. McCarthy, J.B. et al. (1983) MIGRATION BY HAPTOTAXIS OF A SCHWANN-CELL TUMOR LINE TO THE BASEMENT-MEMBRANE GLYCOPROTEIN LAMININ. Journal of Cell Biology 97 (3), 772-777. 
52. Daub, J.T. and Merks, R.M.H. (2013) A Cell-Based Model of Extracellular-Matrix-Guided Endothelial Cell Migration During Angiogenesis. Bulletin of Mathematical Biology 75 (8), 1377-1399.

53. Park, D. et al. (2020) Extracellular matrix anisotropy is determined by TFAP2C-dependent regulation of cell collisions. Nature Materials 19 (2), 227-+.

54. Rot, A. and von Andrian, U.H. (2004) Chemokines in innate and adaptive host defense: Basic chemokinese grammar for immune cells. Annual Review of Immunology 22, 891-928.

55. Tai, G.P. et al. (2018) Electrically stimulated cell migration and its contribution to wound healing. Burns \& Trauma 6.

56. Adams, D.S. et al. (2016) Bioelectric signalling via potassium channels: a mechanism for craniofacial dysmorphogenesis in KCNJ2-associated Andersen-Tawil Syndrome. Journal of Physiology-London 594 (12), 3245-3270.

57. Busse, S.M. et al. (2018) Cross-limb communication during Xenopus hindlimb regenerative response: non-local bioelectric injury signals. Development 145 (19).

58. Pai, V.P. et al. (2018) HCN2 Rescues brain defects by enforcing endogenous voltage pre-patterns. Nature Communications 9.

59. Zhao, M. et al. (2010) Electrical Activation of Wound-Healing Pathways. Advances in Wound Care, Vol 1: Translational Medicine: from Benchtop to Bedside to Community and Back 1, 567-573.

60. Zhao, M. et al. (2006) Electrical signals control wound healing through phosphatidylinositol-3-OH kinase-gamma and PTEN. Nature 442 (7101), 457-460.

61. Zhao, M. (2009) Electrical fields in wound healing-An overriding signal that directs cell migration. Seminars in Cell \& Developmental Biology 20 (6), 674-682.

62. Funk, R.H.W. (2015) Endogenous electric fields as guiding cue for cell migration. Frontiers in Physiology 6.

63. Roca-Cusachs, P. et al. (2013) Mechanical guidance of cell migration: lessons from chemotaxis. Current Opinion in Cell Biology 25 (5), 543-549.

64. Roussos, E.T. et al. (2011) Chemotaxis in cancer. Nature Reviews Cancer 11 (8), 573-587.

65. Swaney, K.F. et al. (2010) Eukaryotic Chemotaxis: A Network of Signaling Pathways Controls Motility, Directional Sensing, and Polarity. Annual Review of Biophysics, Vol 39 39, 265-289.

66. Shellard, A. and Mayor, R. (2016) Chemotaxis during neural crest migration. Seminars in Cell \& Developmental Biology 55, 111-118.

67. Wang, F. (2009) The Signaling Mechanisms Underlying Cell Polarity and Chemotaxis. Cold Spring Harbor Perspectives in Biology 1 (4).

68. Lawson, C.D. and Ridley, A.J. (2018) Rho GTPase signaling complexes in cell migration and invasion. Journal of Cell Biology 217 (2), 447-457.

69. Weber, I. (2006) Is there a pilot in a pseudopod? European Journal of Cell Biology 85 (9-10), 915924.

70. Leslie, N.R. et al. (2005) The regulation of cell migration by PTEN. Biochemical Society Transactions 33, 1507-1508.

71. Tsai, F.C. et al. (2014) A polarized Ca2+, diacylglycerol and STIM1 signalling system regulates directed cell migration. Nature Cell Biology 16 (2), 133-144.

72. Kruse, C.R. et al. (2017) The effect of pH on cell viability, cell migration, cell proliferation, wound closure, and wound reepithelialization: In vitro and in vivo study. Wound Repair and Regeneration 25 (2), 260-269.

73. Garcin, C. and Straube, A. (2019) Microtubules in cell migration. Mechanisms of Cell Migration 63 (5), 509-520.

74. Raab, M. et al. (2012) Crawling from soft to stiff matrix polarizes the cytoskeleton and phosphoregulates myosin-II heavy chain. Journal of Cell Biology 199 (4), 669-683.

75. Plotnikov, S.V. et al. (2012) Force Fluctuations within Focal Adhesions Mediate ECM-Rigidity Sensing to Guide Directed Cell Migration. Cell 151 (7), 1513-1527.

76. Puleo, J.I. et al. (2019) Mechanosensing during directed cell migration requires dynamic actin polymerization at focal adhesions. Journal of Cell Biology 218 (12), 4215-4235. 
77. Wormer, D.B. et al. (2014) The Focal Adhesion-Localized CdGAP Regulates Matrix Rigidity Sensing and Durotaxis. Plos One 9 (3).

78. Hetmanski, J.H.R. et al. (2019) Membrane Tension Orchestrates Rear Retraction in Matrix-Directed Cell Migration. Developmental Cell 51 (4), 460-+.

79. McKenzie, A.J. et al. (2020) Protein kinase A activity is regulated by actomyosin contractility during cell migration and is required for durotaxis. Molecular Biology of the Cell 31 (1), 45-58.

80. Lachowski, D. et al. (2018) FAK controls the mechanical activation of YAP, a transcriptional regulator required for durotaxis. Faseb Journal 32 (2), 1099-1107.

81. Novikova, E.A. et al. (2017) Persistence-Driven Durotaxis: Generic, Directed Motility in Rigidity Gradients. Physical Review Letters 118 (7).

82. Yu, G.Y. et al. (2017) Phenomenological modeling of durotaxis. Physical Review E 96 (1).

83. Hill, T.L. (1987) Linear Aggregation Theory in Cell Biology.

84. Lazopoulos, K.A. and Stamenovic, D. (2008) Durotaxis as an elastic stability phenomenon. Journal of Biomechanics 41 (6), 1289-1294.

85. Shemesh, T. et al. (2005) Focal adhesions as mechanosensors: A physical mechanism. Proceedings of the National Academy of Sciences of the United States of America 102 (35), 12383-12388.

86. Escribano, J. et al. (2018) A hybrid computational model for collective cell durotaxis. Biomechanics and Modeling in Mechanobiology 17 (4), 1037-1052.

87. Sunyer, R. et al. (2016) Collective cell durotaxis emerges from long-range intercellular force transmission. Science 353 (6304), 1157-1161.

88. Mitchison, T. and Kirschner, M. (1988) CYTOSKELETAL DYNAMICS AND NERVE GROWTH. Neuron 1 (9), 761-772.

89. Elosegui-Artola, A. et al. (2014) Rigidity sensing and adaptation through regulation of integrin types. Nature Materials 13 (6), 631-637.

90. Vincent, L.G. et al. (2013) Mesenchymal stem cell durotaxis depends on substrate stiffness gradient strength. Biotechnology Journal 8 (4), 472-+.

91. Evans, E.B. et al. (2018) Schwann cell durotaxis can be guided by physiologically relevant stiffness gradients. Biomaterials Research.

92. Joaquin, D. et al. (2016) Cell Migration and Organization in Three-Dimensional In Vitro Culture Driven by Stiffness Gradient. Biotechnology and Bioengineering 113 (11), 2496-2506.

93. Wu, C.Y. et al. (2012) Arp2/3 Is Critical for Lamellipodia and Response to Extracellular Matrix Cues but Is Dispensable for Chemotaxis. Cell 148 (5), 973-987.

94. King, S.J. et al. (2016) Lamellipodia are crucial for haptotactic sensing and response. Journal of Cell Science 129 (12), 2329-2342.

95. Lo, C.M. et al. (2004) Nonmuscle myosin IIB is involved in the guidance of fibroblast migration. Molecular Biology of the Cell 15 (3), 982-989.

96. Chan, K.T. et al. (2014) LKB1 loss in melanoma disrupts directional migration toward extracellular matrix cues. Journal of Cell Biology 207 (2), 299-315.

97. Poo, M.M. and Robinson, K.R. (1977) ELECTROPHORESIS OF CONCANAVALIN-A RECEPTORS ALONG EMBRYONIC MUSCLE-CELL MEMBRANE. Nature 265 (5595), 602-605.

98. Allen, G.M. et al. (2013) Electrophoresis of Cellular Membrane Components Creates the Directional Cue Guiding Keratocyte Galvanotaxis. Current Biology 23 (7), 560-568.

99. Zhao, M. et al. (2002) Membrane lipids, EGF receptors, and intracellular signals colocalize and are polarized in epithelial cells moving directionally in a physiological electric field. Faseb Journal 16 (6), 857-+.

100. Liu, Q. and Song, B. (2014) Electric field regulated signaling pathways. International Journal of Biochemistry \& Cell Biology 55, 264-268.

101. Mycielska, M.E. and Djamgoz, M.B.A. (2004) Cellular mechanisms of direct-current electric field effects: galvanotaxis and metastatic disease. Journal of Cell Science 117 (9), 1631-1639.

102. Nakajima, K. et al. (2015) KCNJ15/Kir4.2 couples with polyamines to sense weak extracellular electric fields in galvanotaxis. Nature Communications 6. 
103. Huang, Y.J. et al. (2016) Cellular microenvironment modulates the galvanotaxis of brain tumor initiating cells. Scientific Reports 6.

104. Gardiner, E.M. et al. (2002) Spatial and temporal analysis of Rac activation during live neutrophil chemotaxis. Current Biology 12 (23), 2029-2034.

105. Srinivasan, S. et al. (2003) Rac and Cdc42 play distinct roles in regulating PI(3,4,5)P-3 and polarity during neutrophil chemotaxis. Journal of Cell Biology 160 (3), 375-385.

106. Rajnicek, A.M. et al. (2006) Temporally and spatially coordinated roles for Rho, Rac, Cdc42 and their effectors in growth cone guidance by a physiological electric field. Journal of Cell Science 119 (9), 1723-1735.

107. Pullar, C.E. et al. (2006) beta 4 integrin and epidermal growth factor coordinately regulate electric field-mediated directional migration via Rac1. Molecular Biology of the Cell 17 (11), 4925-4935.

108. Zimolag, E. et al. (2017) Electric field as a potential directional cue in homing of bone marrowderived mesenchymal stem cells to cutaneous wounds. Biochimica Et Biophysica Acta-Molecular Cell Research 1864 (2), 267-279.

109. Brahmbhatt, A.A. and Klemke, R.L. (2003) ERK and RhoA differentially regulate pseudopodia growth and retraction during chemotaxis. Journal of Biological Chemistry 278 (15), 13016-13025. 110. Yan, T. et al. (2018) Integrin v3-associated DAAM1 is essential for collagen-induced invadopodia extension and cell haptotaxis in breast cancer cells. Journal of Biological Chemistry 293 (26), 1017210185.

111. Hammerick, K.E. et al. (2010) In vitro effects of direct current electric fields on adipose-derived stromal cells. Biochemical and Biophysical Research Communications 397 (1), 12-17.

112. Cho, Y. et al. (2018) Electric field-induced migration and intercellular stress alignment in a collective epithelial monolayer. Molecular Biology of the Cell 29 (19), 2292-2302.

113. Caballero, D. et al. (2015) Ratchetaxis: Long-Range Directed Cell Migration by Local Cues. Trends in Cell Biology 25 (12), 815-827.

114. Lo Vecchio, S. et al. (2020) Collective Dynamics of Focal Adhesions Regulate Direction of Cell Motion. Cell Systems 10 (6), 535-+.

115. Pieuchot, L. et al. (2018) Curvotaxis directs cell migration through cell-scale curvature landscapes. Nature Communications 9.

116. Park, J. et al. (2018) Topotaxis: A New Mechanism of Directed Cell Migration in Topographic ECM Gradients. Biophysical Journal 114 (6), 1257-1263.

117. La Maout, E. et al. (2020) Ratchetaxis in channels: cells move directionally by pushing walls asymmetrically. bioRxiv. https://doi.org/10.1101/2020.04.03.023051.

118. Bajanca, F. et al. (2019) In vivo topology converts competition for cell-matrix adhesion into directional migration. Nature Communications 10.

119. Shirke, P.U. et al. (2019) "Viscotaxis"- c of SDF-1 alpha and EGF Gradients on Tumor Cell Migration Revealed by a Robust 3D Microfluidic Model. Plos One 8 (7).

121. Comelles, J. et al. (2014) Cells as Active Particles in Asymmetric Potentials: Motility under External Gradients. Biophysical Journal 107 (7), 1513-1522.

122. Wondergem, J.A. et al. (2019) Chemotaxis and topotaxis add vectorially for amoeboid cell migration. bioRxiv. https://doi.org/10.1101/735779.

123. Belotti, Y. et al. (2020) Chemotaxis overrides Barotaxis during Directional Decision-Making in Dictyostelium discoideum. bioRxiv. https://doi.org/10.1101/2020.01.14.904748.

124. Pfeffer, W., Locomotorische Richtungsbewegungen durch chemische Reize, Untersuch. Bot. Inst. Tübingen, 1884, pp. 363-482.

125. Engelmann, W., Ueber Assimilation von Haematococcus, Botanische Zeitung, 1882, pp. 419-426. 126. Lo, C.M. et al. (2000) Cell movement is guided by the rigidity of the substrate. Biophysical Journal 79 (1), 144-152.

127. Berry, M.F. et al. (2006) Mesenchymal stem cell injection after myocardial infarction improves myocardial compliance. American Journal of Physiology-Heart and Circulatory Physiology 290 (6), H2196-H2203. 
128. Reig, G. et al. (2017) Extra-embryonic tissue spreading directs early embryo morphogenesis in killifish. Nature Communications 8. 129. Nagel, W.U. (1985) Ueber Galvanotaxis. Pflügers Arch. Bd (59), 603-642.

130. Carter, S.B. (1967) HAPTOTAXIS AND MECHANISM OF CELL MOTILITY. Nature 213 (5073), 256-\&. 131. Bauer, A.L. et al. (2009) Topography of Extracellular Matrix Mediates Vascular Morphogenesis and Migration Speeds in Angiogenesis. Plos Computational Biology 5 (7).

132. Rot, A. (1993) NEUTROPHIL ATTRACTANT ACTIVATION PROTEIN-1 (INTERLEUKIN-8) INDUCES INVITRO NEUTROPHIL MIGRATION BY HAPTOTACTIC MECHANISM. European Journal of Immunology 23 (1), 303-306.

133. Haessler, U. et al. (2011) Dendritic cell chemotaxis in 3D under defined chemokine gradients reveals differential response to ligands CCL21 and CCL19. Proceedings of the National Academy of Sciences of the United States of America 108 (14), 5614-5619.

134. Lamalice, L. et al. (2007) Endothelial cell migration during angiogenesis. Circulation Research 100 (6), 782-794.

135. Blanco-Mezquita, J.T. et al. (2013) Role of Thrombospondin-1 in Repair of Penetrating Corneal Wounds. Investigative Ophthalmology \& Visual Science 54 (9), 6262-6268.

136. Basan, M. et al. (2013) Alignment of cellular motility forces with tissue flow as a mechanism for efficient wound healing. Proceedings of the National Academy of Sciences of the United States of America 110 (7), 2452-2459.

137. Ridley, A.J. (2015) Rho GTPase signalling in cell migration. Current Opinion in Cell Biology 36, 103112.

138. Marin, O. et al. (2010) Guiding Neuronal Cell Migrations. Cold Spring Harbor Perspectives in Biology 2 (2).

139. Bagorda, A. and Parent, C.A. (2008) Eukaryotic chemotaxis at a glance. Journal of Cell Science 121 (16), 2621-2624.

140. King, J.S. and Insall, R.H. (2009) Chemotaxis: finding the way forward with Dictyostelium. Trends in Cell Biology 19 (10), 523-530.

141. Schweinitzer, T. and Josenhans, C. (2010) Bacterial energy taxis: a global strategy? Archives of Microbiology 192 (7), 507-520.

142. Hader, D.P. and Hemmersbach, R. (2017) Gravitaxis in Euglena. Euglena: Biochemistry, Cell and Molecular Biology 979, 237-266.

143. Delong, E.F. et al. (1993) MULTIPLE EVOLUTIONARY ORIGINS OF MAGNETOTAXIS IN BACTERIA. Science 259 (5096), 803-806.

144. Hegemann, P. et al. (1991) ALL-TRANS RETINAL CONSTITUTES THE FUNCTIONAL CHROMOPHORE IN CHLAMYDOMONAS RHODOPSIN. Biophysical Journal 60 (6), 1477-1489.

145. Miki, K. and Clapham, D.E. (2013) Rheotaxis Guides Mammalian Sperm. Current Biology 23 (6), 443-452.

146. Mazzag, B.C. et al. (2003) Model of bacterial band formation in aerotaxis. Biophysical Journal 85 (6), 3558-3574.

147. Moreau, H.D. et al. (2019) Macropinocytosis Overcomes Directional Bias in Dendritic Cells Due to Hydraulic Resistance and Facilitates Space Exploration. Developmental Cell 49 (2), 171-+.

148. Pringault, O. and Garcia-Pichel, F. (2004) Hydrotaxis of cyanobacteria in desert crusts. Microbial Ecology 47 (4), 366-373.

149. Poff, K.L. (1975) THERMOTAXIS BY PSEUDOPLASMODIA OF DICTYOSTELIUM-DISCOIDEUM. Plant Physiology 56 (2), 77-77.

150. Sikora, J. et al. (1992) Two state Model of Paramecium Bursaria Thigmotaxis. Experientia 48, 789792.

151. Li, S. et al. (2002) The role of the dynamics of focal adhesion kinase in the mechanotaxis of endothelial cells. Proceedings of the National Academy of Sciences of the United States of America 99 (6), 3546-3551. 
1 152. Tambe, D.T. et al. (2011) Collective cell guidance by cooperative intercellular forces. Nature 2 Materials $10(6), 469-475$.

3

4 